\title{
Cognitive Narrative Psychotherapy: Research Foundations
}

\author{
Óscar F. Gonçalves and Paulo P. P. Machado \\ University of Minho
}

There has been an increased interest in the study of language processes in psychotherapy. More recently, research and theoretical formulations of the therapeutic process suggested that we must move from the microscopic study of verbal modes to a macroscopic approach in which these modes are organized into narratives. Narratives are conceived, in this perspective, as the basic instruments for meaning making. In this article the research on narrative processes in psychotherapy is reviewed and discussed in terms of its implications for the theory and practice of cognitive narrative psychotherapy. Additionally some of the main data coming from research projects on cognitive narrative psychotherapy are presented. () 1999 John Wiley \& Sons, Inc. J Clin Psychol 55: 1179-1191, 1999.

During the last decades there has been an increased interest in the study of language processes in psychology, such as conversational, discursive, and narrative (cf., Bruner, 1991; Harré \& Gilbert, 1994; Howard, 1991; Polkinghorne, 1988; Sarbin, 1986; Shotter, 1995). This emphasis in language as a first-order psychological phenomenon is partly due to the growing influence of constructivist and social constructionist theory. According to these perspectives, human beings actively construct their knowledge using "language games." In this sense, cognitions are conceived not as a process of mental representation but, instead, as an open and active embodied language. Language is not seen as a mere by-product but as the psychological phenomenon in itself. Harré and Gillet (1994) refer to this emphasis on language as "the discursive turn." "Discursive phenomena, for example, acts of remembering, are not manifestations of hidden subjective, psychological phenomena, they are the psychological phenomena" (p. 27).

We construct knowledge and meaning by developing language games. These language games are, in human beings, organized as narratives. The narrative constitutes a

Correspondence concerning this article should be addressed to Óscar F. Gonçalves, Departamento de Psicologia, Universidade do Minho, 4700 Braga, Portugal; e-mail: goncalves@iep.uminho.pt. 
way of introducing some kind of order in the face of the chaotic nature of experience (Gonçalves, 1997 a; Gonçalves, Korman, \& Angus, in press). Therefore, understanding narrative can be fundamental for understanding the way humans construct and organize their knowledge and experience.

It is recognized that narrative is an epigenetic phenomenon. In other words, psychological development is correlated with the ability to elaborate narratives in an increasingly complex way. At a very early age children develop the ability and need to represent their daily meaning through a narrative process (c.f., Sutton-Smith, 1986). Research in developmental psychology indicates that children develop a narrative grammar (Mandler, 1984) through which they impose a narrative structure for both real and symbolic daily events. For example, Stein and Nezworski (1978) show in their studies that cognitive efficiency (e.g., memory) is dependent on the narrative grammar structure. In sum, research tends to emphasize the fact that from a very early age human beings tend to impose meaning to daily episodes through a narrative grammar and that knowledge development parallels the development of this structure (c.f., Garate-Larrea, 1994).

Recently, numerous psychotherapeutic strategies, coming from diverse theoretical traditions, have framed the therapeutic process in terms of narrative. Examples include Gonçalves' (1995a) cognitive narrative psychotherapy, Schafer's (1992) narrative formulation of psychodynamic therapy, and White and Epston's (1990) narrative therapy within the systemic tradition. We are also witnessing a growing interest, both in theory and research, in client and therapist's narratives (cf., McLeod, 1997; Toukmanian \& Rennie, 1992). In spite of the early attention psychotherapy researchers to the language processes, the study of narrative has been left out of mainstream process research. As it was noted by Rennie and Toukmanian (1992) in a conceptual review of the psychotherapy process:

In the history of psychotherapy process research and of psychology generally, the paradigmatic approach has prevailed; the use of the narrative approach is relatively new and comparatively untried. Yet its major appeal is that it inherently addresses meaning and is thus in principle more suitable as a way of understanding the psychotherapeutic process at what we refer to below as the first level of reduction in explaining human behavior-the level of the person (p. 235).

In the current article we will review some of the main research on narratives in psychotherapy. Then we will discuss how these apply to the process of cognitive narrative psychotherapy. And finally, we will present current research projects on cognitive narrative psychotherapy.

\section{Research Foundations}

In order to explore the importance of the emerging narrative metaphor to psychotherapy, two issues need to be discussed: (1) the role of narrative in the therapeutic process, and (2) are certain narratives processes more therapeutic than others?

\section{The Role of Narrative in the Therapeutic Process}

Luborsky, Barber, and Diguer (1992) have explored both the nature and meaning of narratives on a sample of patients from two major psychotherapeutic research projects. Two independent judges identified in each therapeutic transcript several instances of complete relationship narratives (i.e., description of a relationship episode with details on the exchange between the self and other in terms of wishes and responses, along with descriptions about the outcome). These narratives were further analyzed using the 
Core Conflictual Relationship Theme (CCRT) method in order to clarify the meaning of the narratives. Two aspects of the results are worth mentioning here. On a descriptive level, the results of this study show that patients told an average of four to seven narratives per session, and each narrative lasted for about four to six minutes. Additionally, these narratives were mostly about recent events, often interactions with closely related people.

Several findings reported by Luborsky et al. (1992) concerning the internal dimensions of the narratives are worth noting: a) there are some relationship patterns that are pervasive across narratives; $b$ ) these patterns are expressed both in waking narratives and dream reports; c) these patterns are apparent both in the narratives told inside and outside therapy; and d) the pattern of narratives told about the therapist are similar to those about other people. The authors conclude from this data that "within these narratives is embedded a general relationship pattern or schema with structural or trait-like properties" (p. 287).

Finally, some of the data suggests that therapy outcome is significantly related to the relationship narratives - namely, there are changes in the narratives from the negative to the positive components of CCRT, and those changes are significantly associated with measures of psychotherapeutic outcome.

Rennie's research attempts to go beyond the descriptive analysis of narrative processes in psychotherapy by addressing the nature of the client's subjective experience during the narrative process (Rennie, 1992). In one study, Rennie (1992) investigated clients' subjective experiences of storytelling through the analysis of 16 therapeutic transcripts of clients working within different therapeutic modalities (i.e., person centered, gestalt, transactional analytic, radical behaviorist, rational emotive, and eclectic). Clients reported on their moment-to-moment experience of storytelling using the Interpersonal Process Recall methodology. The reports of this moment-to-moment experience were the object of qualitative analysis. Several clusters of categories emerged from the analysis such as distancing from disturbance (i.e., delaying the entry into the disturbance; managing beliefs associated with the disturbance) and storytelling as therapeutic experience (i.e., emotional relief; contact with the inner disturbance; private processing of experience).

In sum, analysis of the subjective experience of narrative in psychotherapy reveals a complex set of cognitive and emotional processes including thoughts, feelings, and thoughts about thoughts and feelings about feelings (cf. Rennie, 1992).

This line of research indicates that narratives are pervasive phenomena in psychotherapy. Not only most of what goes on in psychotherapy is an exchange of narratives, but these narratives seem to be illustrative and inclusive of basically all processes of meaning constructions: about awake and dream states; about the self, others or therapist; and about both the present or the past. The fundamental therapeutic functions that it has been shown to accomplish, emotional experiencing and relief as way of working through thought and feelings, justify the pervasiveness of narrative.

\section{The Therapeutic Nature of Clients' Narratives}

In order to study the role of narrative processes across different types of psychotherapy, Angus and coworkers have constructed the Narrative Process Coding System (NPCS) (Angus, Hardtke, \& Levitt, 1992b; see also Angus \& Hardtke, 1999). After dividing the therapy transcript into topic segments, each segment is coded in one of three mutually exclusive narrative modes: focus on the external/event (i.e., description of an event or 
issue); focus on the internal (i.e., elaboration on subjective experiences); and focus on the reflexive (i.e., interpretation of either external events or subjective experiences). As the authors note, one of the strengths of this coding system is that it permits analysis of different modalities of therapy or outcomes as they are related to different narrative modes.

In a pilot study, three good-outcome and three poor-outcome Brief Psychodynamic therapies were analyzed with the NPCS. The third, fifth, and fifteenth session from each dyad were selected for analysis in this study. Their findings have revealed some interesting patterns. The poor-outcome group had a greater overall percentage of internal and external narrative sequences compared to the good-outcome group. The good-outcome group had a progressively higher percentage of the reflexive mode compared to the poor-outcome group. An increase on reflexive narrative sequences seems to be related with a better outcome.

The research presented thus far points in the direction of the therapeutic effectiveness of narratives or certain narrative modes. The research program currently directed by James Pennebaker on the therapeutic effects of writing and talking about core personal narratives on a number of physical and psychological health measures further extend our understanding of the therapeutic role of narrative (cf., Pennebaker, 1993; see also Pennebaker \& Seagel, 1999).

The following paradigm is typical in these studies: subjects are assigned to write about highly personal topics for periods of 3-5 consecutive days, for 15-20 minutes a day. These subjects are compared on a number of outcome measures with control subjects who are invited to write on superficial topics. These studies reached consistent conclusions that support the notion that experimental subjects who write about deep personal topics have highly significant changes in terms of several clinically relevant measures. For example, subjects who write about their personal experiences experience a significant drop in health center visits for periods up to six months (Pennebaker \& Beall, 1986), demonstrate improvements in their immune system (Pennebaker, Kiecolt-Glaser, \& Glaser, 1988), have fewer absences from work and improved enzyme function for up to two months (Francis \& Pennebaker, 1992), experienced improvement of physical health and grade-point average (Pennebaker, Colder \& Sharp, 1990). An interesting finding from all this research was that the improvements in physical health experienced by experimental subjects was not due to dramatic changes in their behavior (including their drinking, sleeping, smoking, and exercise patterns).

In order to clarify why narratives have positive effects, Pennebaker and colleagues undertook a set of studies exploring the analysis of word usage by subjects. In order to explore the word usage, the author selected subjects from samples of previous studies that tended to improve in all outcome measures and contrasted these cases with subjects who were least likely to show improvement. A total of 208 essays were analyzed through a comprehensive text analysis program, Linguistic Inquiry and Word Counts (LIWC). Several results are noteworthy. First, the group that improved presented significantly higher use of negative-emotion words and a lower usage of positive-emotion words. Second, across the 3-4 days of writing, the low-improvement group shows an increased usage of positive-emotion words. Third, highly improved and low-improved subjects did not differ globally on the use of insight, causal, and other self-reflective cognitive words. However, the highly improved sample revealed an increase in the use of more cognitive words across the days of writing. Finally, improved subjects revealed a significant drop in the use of unique words (i.e., actual number of different words that a person uses divided by the total number of words) across the writing sessions. Additional analysis of the narratives by judges, besides confirming the above data, have shown that highly improved subjects experienced increases across sessions of writing in the ratings of organization, 
acceptance, and optimism. Personal disclosure of negative emotions and the progressive construction of a clear and meaningful cognitive narrative seem to be the central components of therapeutic writing.

Several implications can be drawn from the research presented:

(1) Clients seem to use narrative as a mode of expressing the idiosyncratic aspects of their phenomenology;

(2) narratives shared by clients in psychotherapy are fundamental for the accomplishment of central therapeutic tasks;

(3) different narrative modes seem to be associated with distinct therapeutic results, with good outcome being associated with increasing levels of coherence, internally, and reflexivity.

\section{Cognitive Narrative Psychotherapy}

Pennebaker concludes an overview of his research with a meaningful statement:

The recent social construction [...] and narrative [...] explanatory models are conditionally supported in our findings. However, holding a coherent narrative to explain a traumatic or upsetting experience may not always be healthy at the beginning of therapeutic writing sessions. Movement towards the development of a narrative is far more predictive of health than having a coherent story per se. The construction of a story rather than having a constructed story, then, may be the desired endpoint of writing and, by extension, some therapy (1993, p. 546).

Recent developments in cognitive therapy have acknowledged both the central role of narrative in cognitive organization as well as the need to structure the therapeutic process in a narrative way (e.g., Gonçalves, 1995b, Meichenbaum, 1995; Russell, 1991). In what follows we begin by presenting some historical background for cognitive narrative psychotherapy and its central assumptions and foundations and then present the general structure of cognitive narrative psychotherapy.

\section{Historical Background, Foundations, and Assumptions}

Cognitive narrative psychotherapy started as an effort to conciliate both classical cognitive therapy and those who emphasized the importance of metaphors and narratives in the therapeutic process (c.f., Gonçalves, 1989; Gonçalves \& Machado, 1987; Gonçalves \& Santos, 1987; Gonçalves \& Craine, 1990). At that time we were trying to use more analogical methods that were aimed directly to produce change at a more tacit level of knowledge organization.

In the initial formulations of this model, the therapist devised carefully his/her own metaphors and narratives in order to produce intentionally changes in the client. As this method evolved it became apparent that more important than the narrative mode of the therapist was the opportunity to create conditions for the clients to develop their own more coherent, complex, and diversified narrative elaboration. In other words, if knowledge was conceptualized as the result of a narrative's discursiveness, maybe the key was to help clients in the elaboration of their own narratives. We then developed what we called cognitive narrative therapy. Cognitive because we assume the inseparability of existence and knowledge, in the sense that all living creatures are theories of their environment (Weimer, 1977), and narrative because we believe that it is through narrative that knowledge organizes and transforms itself (Gonçalves, 1995a, 1995b, 1995c, 
1995d, 1995e, 1995f, 1997a, 1997b). There are several assumptions of cognitive narrative psychotherapy that are confirmed by data from the research presented above:

1) narrative constitutes the main vehicle by which clients construct meaning in the therapeutic process;

2) the objective of psychotherapy should be to help clients with the construction of more coherent (narrative connectedness), complex (different narrative modes), and diverse narratives (multiple narrative contents);

3) the therapeutic process is organized to help the client come up with a multiplicity of narrative contents, explore the variety of narrative modes (a progressive direction from more external to more internal and reflexive), and be able to come up to alternative ways of constructing coherence out of their narratives.

Cognitive narrative therapy tries to accomplish these objectives by organizing the therapeutic process into five phases: 1) recalling narratives; 2) objectifying narratives; 3 ) subjectifying narratives; 4) metaphorizing narratives; and 5) projecting narratives.

In recalling narratives, clients develop a recalling attitude, learning how to use past and daily experiences as important tools for meaning making. Through several therapeutic exercises, clients recollect significant narratives across their life span and select one for further analysis. The selected narrative is expected to be a prototype or best example.

The second phase, objectifying narratives, helps clients in the development of an objectifying attitude, allowing them to identify the sensorial and behavioral dimensions of their narratives (e.g., visual, auditory, olfactory, gustatory, kinesthetic, behavioral). The goal is not to develop an objectivist, photographic, true representation of existence; instead, clients are encouraged to empower the complexity of their ontology by discriminating against the network of experiences. Clients are instructed in the development of this objectifying attitude and taught to apply this learning to deepen the analysis of their selected prototype narratives.

The third stage consists of subjectifying narratives. The idiosyncratic nature of every narrative is characterized by the inner experiences of the characters, both cognitive and emotional. The internal side of experience is often referred to as one of the essential dramatic tools for the construction of meaning out of every narrative. Clients learn how to construct their narrative emotional experiences by the experiential strategies of activation, focusing and symbolizing. Additionally, they get acquainted with instruments for constructing the cognitive dimension of the narrative, such as thought listing and downward arrow. Both these processes are applied to the analysis of the selected prototype narrative.

As clients move through this process, they get progressively closer to effective meaning construction. Meaning making is indeed the central objective of the fourth phase of the therapeutic process-metaphorizing narratives. Metaphors are seen as ideal meaningmaking symbols that are isomorphic with the content of the narrative. The objective is therefore to help clients in developing structural, orientation, and physical metaphors that ideally symbolize the meaning construction process in any narrative.

After learning how to develop creatively meaning making metaphors in their experiences, clients turn to their prototype narrative and are instructed to construct their most central root metaphor (metaphor of the prototype narrative).

At this point in therapy, clients have constructed a prototype narrative with the objectivity of sensorial and behavioral details, the complexity of emotional and cognitive subjectivity, and the underlying meaning of a root metaphor. Additionally, they are supposed to have developed the capacity to empower their narratives through the construction of meaning from past, current, and forthcoming experiences. The final stage- 
projecting narratives - aims to help clients in the development of alternative meaningful metaphors and to test these meanings through the projection of new narratives. The final objective is to direct the client into forthcoming life narratives and bring a sense of acting and authorship. Then the client is invited through the projecting attitude to develop new alternative characters (i.e., alternative metaphors) and then to develop and experiment with new narrative scripts that rise out of these new metaphors. After identifying alternative meanings through new metaphors, clients are invited to objectify and subjectify these metaphors. Once this is accomplished, clients try out these projective narratives and the experiences are evaluated by means of a new narrative elaboration.

Through the process of cognitive narrative psychotherapy, clients are invited to use their narrative elaboration as the main vehicle for increasing the level of coherence, complexity, and multiplicity of their experiences. It is not the achievement of a definitive narrative that constitutes the objective of therapy, but the empowerment of clients by the identification and practice of narrative tools. These narrative tools are planned to allow clients a never-ending process of narrative constructions as a way of constructing multiple meaning out of their experiences.

\section{Researching Cognitive Narrative Psychotherapy}

Thus far we have reviewed some of the research on narrative in psychotherapy and how this research brings some support to the conceptual and clinical aspects of the cognitive narrative psychotherapy. We will now describe some of the research currently in progress at the University of Minho (Portugal). We will begin by presenting the research on the relationship between prototype narratives and different psychological disorders. Then the results of a research project on the use of cognitive psychotherapy with psychotraumatic aspects of myocardial-infraction patients will be presented. Finally, a current project on the use of cognitive narrative psychotherapy for depression will be introduced.

\section{Narrative and Psychopathology}

If narratives are the essential processes of meaning making, different ways of idiosyncratic meaning making could correspond to different prototype narratives. That is, in different psychopathological situations there would be characteristic meaning-making processes that could be identified in different prototype narratives. In other words, certain key scenes may be constructed as prototypes and these prototypes may rule the subsequent process of cognitive categorization for all the forthcoming experiences. These prototype narratives become perceptographs "ways of symbolically expressing abstract perceptions under the guise of depicting actual historical events" (Bruhn, 1992, p. 4). Even though mostly unconsciously, metaphorically, and analogically represented, the prototype narratives or perceptographs can be translated and deciphered into language if appropriate techniques, such as those utilized in therapy, are used (c.f., Bruhn, 1992). Prototype narratives become scripts to which the individual has to refer continuously in an effort to find coherence and identity in the maze of experiences (cf., Leahy, 1991).

If we assume that different types of cognitive organizations characterize different types of dysfunction, then it may well be possible that different prototype narratives characterize different types of cognitive organizations. In other words, we hypothesize that it is possible to abstract specific prototype narratives from individuals with different psychological dysfunctions (e.g., phobic, obsessive compulsive, depressive, eating disorders, drug dependents).

As an example of how psychopathology can be conceptualized in terms of specific narrative contents, we will now present a research program that we have been pursuing at 
our clinic with the aim of identifying prototype narratives from individuals with different psychological dysfunctions.

In our research program carried out at our laboratory we have interviewed 24 agoraphobic, 18 oppioide dependent, 20 alcoholics, 11 anorexic, and 20 depressed patients. All subjects, currently in psychotherapy and under psychopharmacological treatment, met DSM-IV criteria for these disorders (APA, 1994) as diagnosed by experienced psychiatrists and clinical psychologists.

Significant life narratives were collected from each subject and analyzed using the qualitative methodology of grounded analysis. The process of constructing and validating a prototype narrative followed the six-stage process suggested by Rennie, Philips, and Quartaro (1988). This process is described bellow.

Following diagnosis, subjects were given a structured interview that included a guided imagery process of recall across several life narratives. The subjects were asked to select one of the narratives recalled for further exploration. In the second part of the interview each subject responded to a set of questions regarding the narrative in order to obtain details, both on the external and internal components of the selected experience. All narratives were taped and subsequently transcribed.

Transcripts of the interview were categorized in the seven different dimensions suggested by narrative grammar structure described (Mandler, 1984): setting, initiating event, internal response, goal, actions, outcome, and ending.

The content of the narratives within each dimension of the grammar structure categories was further analyzed in order to allow the identification of different meaning categories. The meaning categories identified in the memoing phase were collapsed further into clusters of hierarchical meanings.

Using the clusters of hierarchical meaning, a prototype narrative for each psychopathological sample was constructed. Finally, psychopathological groups were matched with a equal number of control subjects, were shown the prototype narrative, and were asked to rate on a five-point Likert scale the degree to which that narrative could be understood as something plausible as a personal life event. The most relevant results from this research program are described next.

After categorizing each transcript in the seven dimensions of the narrative grammar structure, the memoing process produced several hundreds of meaning categories. These meaning categories were subsequently the objects of hierarchical categorization. This process of categorization allowed the emergence of seven clusters of hierarchical meaning, one for each dimension of the narrative-grammar structure. Finally, based on the hierarchical categories of meaning, prototype narratives were constructed for each sample. The prototypes were constructed by collapsing the 18 narratives into commonmeaning themes using the seven clusters of hierarchical meaning suggested by the process of hierarchical categorization.

Generally speaking, the prototype narrative for the oppioide-dependent sample can be stated as an episode taking place in a public setting and activated by some uncontrolled situation. Individuals are guided in this situation by the objective of avoiding some painful situation and seeking pleasure. Their actions are typically nonconfrontative and externally controlled, with a compound of internal states oscillating between the dialectics of pain/suffering and pleasure/relief. The outcome of the narrative is typically the maintenance of the status quo, with the subjects ending up with a sense of social loss and loss of personal power.

For the alcoholic sample the prototype narrative can be summarized as an episode taking place in an intimate context and activated by an experience of loss. Individuals are guided in this situation by the objective of overcoming and escaping the situation. Their 
actions are of crying and escaping with accompanying feelings of sadness and tension. The outcome of the narrative is typically the feeling of isolation, with the subjects ending up with a sense that this situation was the beginning of a personal collapse.

The prototype narrative of the anorexic patients is an episode that has the central scenario of the school and the house. It is a situation where they are confronted and disappointed by the attitude of significant others. Subjects try to assert themselves in this confrontation by opposing and crying while experiencing sadness, anxiety, disappointment, and anger. The typical outcome is the failure of the subject to assert his/her own wishes, resulting in a disappointment with themselves and others.

Finally, for the agoraphobic subjects the prototype narrative takes place between hospital and home, and is activated by a situation that is seen as both a separation and a risky challenge. The subjects try to maintain security and overcome this challenge by a mixture of avoidance, crying, and searching for help, while at the same time challenging themselves. They experience in this process a composite of different feelings such as fear, insecurity, loss of control, abandonment, sadness, despair, offence, revenge, and personal affirmation. Individuals try to reassume a sense of calm and tranquility by avoidance, crying, challenging themselves, and searching for help. The situation typically ends with a dichotomous experience: On one side an increased awareness of the dangers, and on the other side the sense of self competence and efficacy.

The computation of the convergent validity of the prototype narratives was done testing the verisimilitude of each prototype narrative for a sample of the dysfunctional and the comparison groups. All subjects were confronted with the prototype narrative and asked to rate on a five-point Likert scale the degree to which that narrative could be understood as something plausible as a personal life event.

The results show that the psychopathological samples evaluate the prototype narrative as significantly more related to their personal lives than the control sample (Oppioide dependents $-X 2=35.9 ; p<.0001$; Alcoholics $-X 2=40.3 ; p<.0001$; Anorexic$X 2=24.67 ; p<.0001 ;$ Agoraphobics $-X 2=41.0 ; p<.0001$; Depressed- $X 2=60.67$; $p<.001)$. Therefore we believe that through the process of grounded analysis it is possible to come up with seven clusters of hierarchical meaning, one for each of the dimensions described in narrative grammar structure. These clusters of meaning guided the construction of prototype narratives for different dysfunctions. A significant level of convergent validity was found for each prototype narratives.

As stated before, an assumption underlying the present research was that some nuclear narratives acquire a central role in knowledge development, assuming the role of core prototypes from which further experiences are categorized, reordered, and intentionalized. The convergent validity found for the prototype narratives for these three types of dysfunction supports the specificity nature of cognitive organization in these dysfunctions as well as to the possibility of identifying this specificity in prototype narratives.

\section{Impact of Narrative Elaboration of the Psychotraumatic Aspects of the Myocardial Infraction on Patients' Physical and Emotional Recovery}

As stated before, the research has shown that the process of narrative elaboration of traumatic events for a period of 3-5 days, 15-20 minutes a day, has an effect on several health-improvement measures, namely: decrease number of health appointments; overall improvements in the immune system; decrease work absenteeism; and improvements in enzymatic activity (e.g., Pennebaker, 1995). Additionally, patients with the most significant improvements seem to be those whose narratives evolve toward an increase in overall coherence, a progressive increase of cognitive and emotional words, as well as a 
progressive increase in causal insight and reflexive modes (e.g., Angus \& Hardtke, 1994; Pennebaker, 1995).

The main objective of this research project was to test the impact of applying a systematic mode of narrative elaboration (i.e., cognitive narrative psychotherapy) on the emotional and physical recovery of patients suffering a myocardial infraction (Gonçalves, Machado, \& Rosas, 1996).

Sixty myocardial-infraction patients leaving the intensive care unit were divided randomly between the treatment (cognitive narrative therapy) and a control group. The narrative group followed a total of 3 daily one-hour sessions of cognitive narrative psychotherapy (objectifying, subjectifying, metaphorizing, and projecting the narrative). The control group was exposed to an equivalent amount of nonstructured discussion sessions on trivial aspects of life. Participants were evaluated using two self-report measures on emotional well being (BDI, BSI) — pretest, posttest, and follow up —and physical well being (PAIS) follow-up. Preliminary results reported elsewhere (Gonçalves, Machado, \& Rosas, 1996) showed that the narrative group improved along several measures of psychological adjustment.

In summary, the current research at the University of Minho and the Center for Cognitive Psychotherapy aims at increasing our understanding of the role of the narrative in the amelioration of physical and psychological conditions of patients with both physical and psychological problems. We expect that this research will shed some light on some of the important variables in the therapeutic process and the effect of narrative strategies in psychotherapy.

\section{Concluding Remarks}

Since immemorial time, human exchange narratives in a process of social and personal development (c.f., Georges, 1995) and from the beginning of psychotherapy the role of narratives has been widely recognized (c.f., Mahoney, 1995b). If psychotherapy is construed as a discursive act, then all psychotherapies have to use narratives as a central therapeutic tool (c.f., Stiles, 1995). It is then time to look at narratives not as an epiphenomenon of the therapeutic process but as central focus of change.

\section{References}

Agrican Psychiatric Association (1994). Diagnostic and statistical manual of mental disorders (4th ed.). Washington, DC: APA.

Angus, L.E., \& Hardtke, K. (1994). Narrative processes in psychotherapy. Canadian Psychology, $35,190-203$.

Angus, L.E., Hardtke, K., \& Levitt, H. (1996). The narrative processes coping system manual: revised edition. Unpublished manuscript. York University, North York, Ontario, Canada.

Angus, L.E., Levitt, H., \& Hardtke, K. (1999). The narrative processes coding system: Research applications and implications for psychotherapy practice. Journal of Clinical Psychology, 55, $1255-1270$.

Bruhn, A.R. (1992). The early memories procedure: A projective test of autobiographical memory, part 1. Journal of Personality Assessment, 58, 1-15.

Bruner, J. (1990). Acts of meaning. Cambridge, MA: Harvard University Press.

Francis, M.E., \& Pennebaker, J.W. (1992). Putting stress into words: The impact of writing on physiological abseuteg, and self reported emotional well being measures. American Journal of Health Promotion, 6, 280-287. 
Garate-Larrea, M. (1994). La comprensión de cuentos en los niños. Madrid: Siglo Veintiuno.

Georges, E. (1995). A cultural and historical perspective on confession. In J. Pennebaker (Ed.), Emotion, disclosure and health. Washington, DC: APA Press.

Gonçalves, O.F. (Ed.). (1989). Advances in the cognitive therapies. Porto, Portugal: APPORT.

Gonçalves, O.F. (1995a). Hermeneutics of the cognitive-behavioral therapies: From the object to the project. In R. Neimeyer \& M.J. Mahoney (Eds.), Constructivism in psychotherapy. Washington, DC: APA.

Gonçalves, O.F. (1995b). Cognitive narrative psychotherapy. In M.J. Mahoney (Ed.), Cognitive and constructive psychotherapies. NY: Pergamon.

Gonçalves, O.F. (1995c). Psicoterapia Cognitiva Narrativa e construção múltipla de conhecimento. Viver Psicologia., 3, 26-27.

Gonçalves, O.F. (1995d). Psicoterapia Cognitiva Narrativa na Adolescência: Tudo menos o silêncio!. Revista Portuguesa de Pedopsiquiatria, 9, 11-17.

Gonçalves, O.F. (1995e). Psicoterapia cognitivo-narrativa. Revista de Psicoterapia,7, 101-112.

Gonçalves, O.F. (1995f). Cognicion, constructivismo y narrativa: En busca de un sentido para las silabas. Revista de Psicoterapia , 7, 45-52.

Gonçalves, O.F. (1997a). Constructivism and the deconstruction of clinical practice. In T.L. Sexton \& B.L. Griffin (Eds.), Constructivist thinking in counseling practice, research and training. NY: Teachers College Press.

Gonçalves, O.F. (1997b). El proceso terapéutico en la psicoterapia cognitiva narrativa. In I. Caro (Ed.), Manual de psicoterapias cognitivas: Estado de la custión y procesos psicoterapéuticos. Madrid: Paidos.

Gonçalves, O.F. (1997c). Postmodern cognitive psychotherapy: From the university to the multiversity. Journal of Cognitive Psychotherapy, 11, 105-112.

Gonçalves, O.F., \& Craine, M.H. (1990). The use of metaphors in cognitive therapy. Journal of Cognitive Psychotherapy, 4, 135-149.

Gonçalves, O.F., Korman, Y., \& Angus, L. (in press). Constructing psychopathology from a cognitive narrative perspective. In J.D. Raskin \& R.A. Neimeyer (Eds.), Constructions of disorder. Washington, DC: APA Press.

Gonçalves, O.F., \& Machado, P.P. (1987). A terapia como co-construção: Das metçforas do cliente às metçforas do terapeuta. Jornal de Psicologia, 6, 14-20.

Gonçalves, O.F., Machado, P.P., \& Rosas, M. (1996). A elaboração narrativa dos aspectos psicotraumçticos do enfarte do miocardio: Um manual terapêutico. Psicologia: Teoria, Investigação e Pratica, 1, 381-392.

Gonçalves, O.F., Machado, P.P., Soares, I., Fernandes, A.C., Pereira, E., \& Pinho, C. (1995). Investigação acerca do impacto da elaboração narrativa dos aspectos psicotraumtaicos do enfarte do miocardio na recuperação física e emocional dos doentes. Lisboa: Junta Nacional de Investigação Científica e Tecnológica.

Gonçalves, O.F., \& Santos, S.B. (1987). O uso da metáfora-múltipla-escondida em terapia cognitiva. Psiquiatria Clínica, 8, 175-184.

Harré, R., \& Gillett, G. (1994). The discursive mind. NY: Sage.

Howard, G. (1991). Cultural tales: A narrative approach to thinking, cross-cultural psychology, and psychotherapy. American Psychologist, 46, 187-197.

Leahy, R.L. (1991). Scripts in cognitive therapy: The systemic perspective. Journal of Cognitive Psychotherapy, 5, 291-304.

Luborsky, L., Barber, J.P., \& Digver, L. (1992). The meaning of narratives told in psychotherapy: The fruit of a new observation unit. Psychotherapy Research, 2, 277-290.

Mahoney, M.J. (Ed.). (1995a). Cognitive and constructive psychotherapies. NY: Pergamon. 
Mahoney, M.J. (1995b). Emotionality and health: Lessons from and for psychotherapy. In J. Pennebaker (Ed.), Emotion, disclosure and health. Washington, DC: APA Press.

Mandler, J.M. (1984). Stories, swifts, and scenes: Aspects of schema theory. Hillsdale, N.J.: Lawrence Erlbaum.

McLeod, J. (1997). Narrative and psychotherapy. London: Sage.

Meichenbaum, D. (1995). Changing conceptions of cognitive behavior modification: Retrospect and prospect. In M.J. Mahowen (Ed.), Cognitive and constructive psychotherapies: Theory, Research and Practice (pp. 20-26). NY: Springer.

Pennebaker, J.W. (1993). Putting stress into words: Health, linguistic, and therapeutic implications. Behaviour Research \& Therapy, 31, 539-548.

Pennebaker, J.W. (Ed.). (1995). Emotion, disclosure and health. Washington, DC: APA Press.

Pennebaker, J.W., \& Beall, S.K. (1986). Confronting a traumatic event: Toward an understanding of inhibition and disease. Journal of Abnormal Psychology, 95, 274-281.

Pennebaker, J.W., Kiecolt-Glasser, J., \& Glaser, R. (1988). Disclosure of traumas and immune function: Health implications for psychotherapy. Journal of Consulting and Clinical Psychology, 56, 239-245.

Pennebaker, J.W., Colder, M., \& Sharp, L.K. (1990). Accelerating the coping process. Journal of Personality and Social Psychology, 58, 528-537.

Pennebaker, J.W., \& Seagal, J.D. (1999). Forming a story: The health benefits of narrative. Journal of Clinical Psychology, 55, 1243-1254.

Polkinghorne, D.E. (1988). Narrative knowing and the human sciences. Albany, NY: SUNY Press.

Rennie, D.L. (1992). Qualitative analysis of the client experience of psychotherapy: The unfolding of reflexivity. In S.G. Toukmanian \& D.L. Rennie (Eds.) Psychotherapy process research: Paradigmatic and narrative approaches (pp. 211-233). London: Sage.

Rennie, D.L., Phillips, J., \& Quartaro, G.K. (1988). Grounded theory: A promising approach to conceptualization in psychology. Canadian Psychology, 29, 139-150.

Rennie, D.L., \& Toukmanian, S.G. (1992). Explanation in psychotherapy process research. In S.G. Tonkmanien \& D.L. Rennie (Eds.), Psychotherapy process research (pp. 234-251). London: Sage.

Russell, R.L. (1991). Narrative, cognitive representations, and change: New directions in cognitive theory and therapy. Journal of Cognitive Psychotherapy, 5, 241-256.

Sarbin, J. (Ed.) (1986). Narrative psychology: The storied nature of human conduct. NY: Praeger.

Schafer, R. (1992). Retelling a life: Narration and dialogue in psychoanalysis. NY: Basic Books.

Schwartz, G.E., \& Kline, J.P. (1995). Repression, emotional disclosure and health: Theoretical, empirical and clinical considerations. In J. Pennebaker (Ed.), Emotion, disclosure and health. Washington, DC: APA Press.

Shotter, J. (1995). Dialogical psychology. In J.A. Smith, R. Harré, \& L. Van Langenhove (Eds.), Rethinking psychology. London: Sage.

Soares, I. (1993). Narrativas protótipo na anorexia nervosa: Estudo exploratório para a compreensão da organização do conhecimento na anorexia nervosa. Tese de Mestrado em Psicologia. Universidade do Minho.

Stein, N.L., \& Nezworski, M.T. (1978). The effects of organization and instructional set on story memory. Discourse Processes, 1, 177-193.

Stiles, W. (1995). Disclosure as a speech act: It is psychotherapeutic to disclose. In J. Pennebaker (Ed.), Emotion, disclosure and health. Washington, DC: APA Press.

Sutton-Smith, B. (1986). Children's fiction making. In T.R. Sarbin (Ed.), Narrative psychology. NY: Praeger.

Terrell, C., \& Lyddon, W.J. (1996). Narrative and Psychotherapy. Journal of Constructivist Psychology, 9, 27-44. 
Toukmanian, S.G., \& Rennie, D.L. (Eds.) (1992). Psychotherapy process research: Paradigmatic and narrator approaches. London: Sage.

Weimer, W.B. (1977). A conceptual framework for cognitive psychology: Motor theories of the mind. In R. Shaw \& J. Bransford (Eds.) Perceiving, acting, and knowing (pp. 267-311). Hillsdale, NJ: Erlbaum.

White, M., \& Epston, D. (1990). Narrative means to therapeutic ends. NY: Norton. 